\title{
FEIRAS EM UM TERRITÓRIO FRONTEIRIÇO: REFLEXÕES SOBRE COMIDAS, FRONTEIRAS E IDENTIDADES
}

\section{STREET MARKETS IN A FRONTIER TERRITORY: REFLECTIONS ON FOOD, BORDERS AND IDENTITIES}

\section{Paola Stefanutti}

E-mail: paola.stefanutti@ifpr.edu.br

Doutora em Sociedade, Cultura e Fronteiras pela Universidade Estadual do Oeste do Paraná e em Beni Culturali, Formazione e Territorio pela Università degli Studi di Roma Tor Vergata

Docente do Instituto Federal do Paraná

ORCID: https://orcid.org/0000-0002-6392-6869

\section{Andressa Szekut}

E-mail: andressaszekut@gmail.com

Pós-doutoranda em Sociedade Cultura e Fronteiras pela Universidade Estadual do Oeste do Paraná

Doutora em Memória Social e Patrimônio Cultural pela Universidade Federal de Pelotas

ORCID: https://orcid.org/0000-0001-7445-6930

\section{Viviane da Silva Welter}

E-mail: viviitaipu@gmail.com

Doutoranda em Sociedade, Cultura e Fronteiras pela Universidade Estadual do Oeste do Paraná ORCID: https://orcid.org/0000-0003-1737-858X

\section{(2) $\odot \Theta(0)$}

Esta obra está licenciada sob uma licença Creative Commons Attribution-NonCommercial-ShareAlike 4.0 International License.

\section{RESUMO}

Esta escrita tem por objetivo refletir sobre indícios alimentares levantados em feiras de um território fronteiriço e relacioná-los com identidades e fronteiras. Faz-se por meio da observação do cotidiano das feiras, histórico, organização, línguas, identidades, socialização; e do registro de práticas alimentares/gastronômicas destes espaços contemplando ingredientes, produtos, técnicas e utensílios. A localidade estudada situa-se na tríplice fronteira entre Brasil, Paraguai e Argentina, por meio da análise de três feiras, uma em cada lado desta fronteira: a Feirinha da JK (BR), a Feria Municipal de Ciudad del Este (PY) e a Feirinha da Argentina (AR). Os percursos desta pesquisa foram moldados através do método indiciário (GINZBURG, 1989, 2006) em práticas do cotidiano (CERTEAU, 2007, 2008). Os resultados apontam estas feiras como 
espaços sociais com sistemas alimentares complexos, em que a comida pode representar identidades, autenticidade, fronteiras entre o Eu e o Outro, adaptação para agradar paladares diversos e ainda ser veículo de continuidade e de transmissão de saberes entre a própria comunidade. Assim, a comida expressa dinâmicas sociais plurais, que estão em constante negociação e transformação.

Palavras-chave: culturas alimentares; fronteira; feiras.

\section{ABSTRACT}

This study aims to reflect on food evidence, from street markets in a frontier territory and relate them to identities and borders. The study was performed by observing the daily life of the street market, history, organization, languages, identities, socialization; and the registration of food/gastronomic practices in these spaces, including ingredients, products, techniques and utensils. The location studied is the triple border between Brazil, Paraguay and Argentina, where three street markets were analyzed, one on each side of this border: Feirinha da JK (BR), Feria Municipal de Ciudad del Este (PY) and Feirinha da Argentina (AR). This research was shaped using the indicative method (GINZBURG, $1989,2006)$ in everyday practices (CERTEAU, 2007, 2008) with ethnographic hints. The results point to these street markets as social spaces, with their complex food systems, in which food can represent identity, authenticity, borders between the Self and the Other, adaptation to be appreciated by different tastes and still be a vehicle for the transmission of knowledge among the community itself. Thus, food expresses plural social dynamics, which are in constant negotiation and transformation.

Keywords: food cultures; frontier; fairs.

\section{INTRODUÇÃO}

A fronteira entre Brasil, Paraguai e Argentina, com seus respectivos municípios de Foz do Iguaçu, Ciudad del Este e Puerto Iguazú, tem despertado o interesse de pesquisadores das mais diferentes áreas, dentre elas as ciências sociais, saúde, geografia, relações internacionais, turismo e gastronomia. A respeito desta última, diversos autores (PIRES; ZANELLA; OLIVEIRA, 2012; SANTOS, 2013; STEFANUTTI, 2015, 2020) têm levantado questionamentos relacionados às dinâmicas alimentares desta fronteira: quais são as culturas presentes, qual sua comida típica, quais seus pratos representativos ou o que se come nessa fronteira. Este também é o interesse deste estudo, resultado de pesquisa de campo ocorrida entre 2017 a 2019 por ocasião do desenvolvimento da tese de doutoramento de uma das autoras. 
A referida fronteira faz parte de uma das nove tríplices fronteiras do Brasil, possui localização geopolítica estratégica, no âmbito do Mercado Comum do Sul (MERCOSUL), sendo a fronteira mais populosa e com melhor infraestrutura urbana dentre as fronteiras da América do Sul. Foz do Iguaçu está entre os destinos mais visitados do Brasil por estrangeiros ${ }^{1}$, Ciudad del Este é a segunda cidade mais importante do Paraguai em número de habitantes e em desenvolvimento econômico ${ }^{2} \mathrm{e}$ Puerto Iguazú subsiste praticamente em função do turismo ${ }^{3}$.

De acordo com Bianchin (2018) a região se caracteriza pelo elevado grau de urbanização, com uma população de mais de 600 mil habitantes, pelos fluxos intensos de veículos, bens, serviços e pessoas mobilizados pelas relações comerciais e pelo turismo. Este último, com relevante representatividade econômica, uma que vez que estas cidades juntas formam uma rede de infraestrutura receptiva, com rodovias interligadas, três aeroportos, mais de 45 mil leitos, além de inúmeras agências de viagem e transporte, sendo destaque no cenário do turismo nacional e internacional.

Ademais do contexto de atividade turística, este espaço fronteiriço também tem como característica a recente colonização do território, imemorialmente ocupado por comunidades indígenas; e a fixação de diversos fluxos populacionais, principalmente a partir do início do século XX, mas que se estendem até a atualidade, com diferentes motivações, como a fuga de conflitos civis de seus países de origem, a necessidade de trabalho ou de estudo.

Os diversos fluxos populacionais que se deram ao longo dos anos têm sido tanto nacionais, dos três países, quanto internacionais, o que resultou em uma forte presença de populações flutuantes - aspectos que caracterizam este espaço como uma região metropolitana transfronteiriça, o que conforma um cenário ao mesmo tempo plural e singular, formando-se, assim, um espaço de múltiplas fronteiras e interações, múltiplas identidades e consequentemente múltiplos sistemas alimentares.

Como sistemas alimentares parte-se da concepção dos antropólogos Contreras e Gracia (2011, p. 36) que os entendem como: “[...] o complexo das relações interdependentes associadas à produção, distribuição e consumo dos alimentos que foram se estabelecendo ao longo do tempo e do espaço com o objetivo de resolver as necessidades alimentares das populações humanas". Portanto, não são sistemas fechados em si mesmos, mas abertos às dinâmicas sociais, culturais, econômicas e políticas que vão se constituindo em um determinado espaço.

Territórios fronteiriços são propícios para a observação de sistemas alimentares e sua dinamicidade, pois muitas vezes estão envoltos em negociações de identidade, de poder e de representações, principalmente quando há a presença de populações flutuantes.

$\mathrm{Na}$ tríplice fronteira estudada, observam-se estas negociações devido às construções de discursos representacionais variados, como de integra- 
ção e afirmações identitárias, ao mesmo tempo que passa por ressignificações dos elementos que a compõem como território. As ações de patrimonialização alimentar neste espaço são um exemplo da construção de discursos representacionais, uma vez que houve desarticulação entre a comunidade local e os propositores das ações. No website da prefeitura de Foz do Iguaçu ${ }^{4}$ e no Inventário Técnico de Estatísticas Turísticas (FOZ DO IGUAÇU, 2014) consta que os dois pratos típicos de Foz do Iguaçu são o Pirá de Foz e o Dourado Assado, informação que é replicada em blogs, websites e revistas de turismo. Sganzerla e Strasburger (2004, p. 42) também reforçam este imaginário, afirmando que "Os rios Paraná e Iguaçu, mais a Oeste e Noroeste, garantem o dourado e o pintado que, de muitas maneiras, viraram tradição de Foz do Iguaçu e municípios adjacentes ao lago de Itaipu”. Todavia, a proporção das águas não é vista no consumo dos moradores locais, na atualidade. Isto fica evidente pelo número de açougues versus o número de peixarias, o tamanho do espaço físico nos supermercados quanto à comercialização de peixes versus carne bovina, suína e de aves, e no espaço dedicado aos pescados nos cardápios dos restaurantes da cidade, com exceção do uníssono salmão chileno. Aliás, o Pirá de Foz e o Dourado Assado são mais encontrados nas escritas mencionadas do que nos cardápios dos restaurantes, nas feiras locais ou nas cozinhas dos moradores do município.

Dentre as inúmeras possibilidades de recorte para se discutir culturas alimentares da localidade optou-se pela abordagem a partir das feiras. Neste local é onde se escolhem e se compram os ingredientes; onde normalmente prova-se, degusta-se e come-se; onde as conversas, por vezes, giram em torno do assunto alimentação: como preparar melhor aquele produto, com qual tempero combina mais, como armazená-lo da melhor maneira, quanto tempo dura e, por aí, a conversa estende-se até onde ambos, feirante e cliente, podem e querem. Pesquisar a partir de feiras é partir de um detalhe, de uma perspectiva micro que se expande tanto quanto se pode e se quer expandir.

Assim, estudar feiras é uma forma de registrar práticas alimentares do cotidiano, muitas vezes silenciadas e dar visibilidade a personagens à margem das cidades e das fronteiras. Entende-se que as feiras são áreas de produção (modos de fazer), de distribuição e de consumo dos produtos, no caso, das comidas de feiras. Um encontro entre produtores, comerciantes e consumidores, um vasto espaço para os estudos sociais. A feira é espaço de encontro, de socialização, de integração.

Desta forma, objetiva-se refletir sobre indícios alimentares, levantados em feiras de um território fronteiriço e relacioná-los com identidades e fronteiras. Faz-se por meio da observação do cotidiano das feiras, histórico, organização, línguas, identidades, socialização; e do registro de práticas alimentares/gastronômicas destes espaços contemplando ingredientes, produtos, técnicas e utensílios. 
Foram analisadas três feiras, uma em cada lado da fronteira, sendo elas: a Feirinha da JK (BR), a Feria Municipal de Ciudad del Este (PY) e a Feirinha da Argentina (AR). A sequência de apresentação segue a ordem cronológica das visitas às feiras.

Os percursos desta pesquisa foram moldados através do método indiciário (GINZBURG, 1989, 2006) em práticas do cotidiano (CERTEAU, 2007, 2008).

Carlo Ginzburg é referência na utilização do método indiciário. Em seu livro Mitos, Emblemas, Sinais: morfologia e história o autor esmiúça os princípios do paradigma indiciário. Ginzburg (1989, p. 149), com base em Freud, atesta que o método indiciário seria um "[...] método interpretativo centrado sobre os resíduos, sobre os dados marginais, considerados reveladores". Em tal método, informações que estão à margem (leia-se à margem geográfica e social) podem ser reveladoras. Tais informações marginais podem nos mostrar o que o centro, a ideia central, já encobriu, inviabilizando qualquer possibilidade de pensar além do dito, do pintado, do comido.

Ginzburg (1989, p. 151) faz ainda uma analogia, quanto às raízes do método indiciário, com o homem caçador que "aprendeu a farejar, registrar, interpretar e classificar pistas infinitesimais como fios de barba. [...] Gerações e gerações de caçadores enriqueceram e transmitiram esse patrimônio cognoscitivo". Nessa concepção do caçador farejador e identificador de rastros e sinais, faz-se a analogia do pesquisador como um caçador, como ser que utiliza o método venatório. Então, o seu dever é decifrar, compreender, analisar, responder ou inquietar mais sobre um determinado assunto.

Se Ginzburg é fundamental nesta escrita com o método indiciário, o historiador francês Michel de Certeau (1925-1986) também o é na mesma medida em que trata das práticas do cotidiano. Certeau (2007, p. 37) buscou tornar o tema das práticas cotidianas em algo tratável, em: "[...] fornecer, a partir de sondagens e hipóteses, alguns caminhos possíveis para análises ainda por fazer". Para isto, as práticas ou "maneiras de fazer" cotidianas deveriam parar de aparecer como pano de fundo da atividade social para se tornar objeto a ser estudado, algo na mira dos grandes holofotes do palco cênico da vida cotidiana.

Para tal, a pesquisa contou com observação participante nas feiras, registros em diário de campo e registros fotográficos, diálogos com os feirantes e com quem feirava e entrevista com os responsáveis de cada uma das três feiras.

Compreende-se que, para entender a fronteira e seus fenômenos, é essencial olhar para os sujeitos e seus cotidianos. A experiência do método indiciário proporcionou não apenas observar as sutilezas e os pormenores para descrever as características destas feiras, mas evidenciou, igualmente, aspectos além dos alimentares, como as (re)construções identitárias e de fronteiras entre os sujeitos que vivem esse espaço. São práticas do espaço. 


\section{AS FEIRAS}

A Feirinha da JK acontece todos os domingos pela manhã na Avenida Juscelino Kubitschek, em Foz do Iguaçu. Segundo informações no website da Prefeitura de Foz do Iguaçư ${ }^{5}$, a feira existe desde 1986 e já passou por diversos endereços na cidade. A feira possui atualmente 200 expositores, dos quais 100 são categorizados como artesanato e os demais como alimentação. Destes, 50 são produtos in natura ou manufaturados oferecidos por feirantes-produtores e feirantes-intermediários e 50 são produtos prontos para consumo ou comidas de feira.

Das possibilidades de comidas de feira verifica-se particularidades nacionais e regionais como: barraca árabe, de Hong Kong, de Taiwan, do Japão, da Venezuela e da Itália; e de Minas Gerais, da Bahia, de Pernambuco, do Rio Grande do Sul e de Goiás. A Feirinha da JK é marcada pelos migrantes de perto e de longe e por suas comidas. Ressalta-se que também há comidas e bebidas mais comumente encontradas nas feiras brasileiras, como pastel e caldo de cana.

A Feria de Ciudad del Este ocorre de quarta-feira a sexta-feira, sendo que na quarta-feira funciona de 12:00 às 21:00, ou até haver clientes; na quinta, funciona nos três turnos e na sexta se encerra às 12:00. A Feria está localizada atrás do Terminal de Ônibus da cidade e ao lado do estádio de futebol Três de Febrero, estando a $3 \mathrm{~km}$ do centro comercial. Pelo horário de funcionamento, pelas distâncias dos distritos de onde vêm os feirantes (alguns se situam a mais de $150 \mathrm{~km}$ da Feria), e pelo custo do deslocamento, a maioria dos produtores dorme na própria feira. Ao longo do espaço é possível ver, atrás das bancas, colchões dobrados ao meio. O galpão se torna um grande dormitório depois do fechamento, como apontado por um dos coordenadores da feira, Benites (2019).

A Feria de Ciudad del Este comporta duas feiras opostas entre si: a Feria de Produtores denominada Central de Produtores e Feirantes Hortigranjeiros (CPFH) do Alto Paraná e a Feria Permanente. A Feria de Produtores é uma feira agroecológica cujos produtos advêm de pequenos produtores que cultivam sem a utilização de agrotóxicos, prezam pela diversidade e valorizam e promovem as sementes tradicionais. É também uma espécie de farmers' market ${ }^{6}$, um mercado de agricultores/produtores da própria região, em que quem vende é também quem produz, em uma cadeia curta de produção, sem intermediários. O produto vendido é local, é da região, é do território. Segundo a organização não governamental Red Rural de Organizaciones Privadas de Desarrollo ou apenas Red Rural (2016), trata-se de uma das experiências agroecológicas mais expressivas do Paraguai, com cerca de 400 produtores envolvidos.

Já a Feria Permanente comercializa produtos industrializados, como macarrão, farinha de trigo, sal, óleo vegetal, erva-mate e produtos de limpeza como sabão em pó e papel higiênico. Nesta feira também são vendidos produtos hortigranjeiros que são provenientes da CEASA (Centrais Estaduais de Abastecimento) de Foz do Iguaçu. 
Ou seja, produtos agroecológicos e produtos do agronegócio compartilham o espaço. Os formatos, as cores, os aromas e a plasticidade desses produtos e o contraste entre o artificial, o natural, a perfeição e o defeito são aspectos e características a serem debatidos e ruminados. As diferenças são gritantes, não são vestígios, são fatos explícitos. $\mathrm{O}$ fluxo de alimentos da CEASA brasileira até a Feria de Ciudad del Este gera inúmeros conflitos entre produtores e comerciantes, sendo inclusive relatado nos jornais paraguaios como o "contrabando" de alimentos7.

Nesta Feria há ainda o Pátio de Comidas, um espaço separado para comercialização e consumo de comidas prontas. As comidas ali presentes são comidas do cotidiano paraguaio como vori vori, talharim com caldo de galinha, chipa, tortilha de milho, chipa guasu assada na folha de bananeira e/ou a famosa sopa paraguaia, pamonha, marinera (carne milanesa), cabeça de porco, enrolado de porco e hambúrgueres, sanduíche (bife ou frango à milanesa), além de frituras como carnes, peixes e empanadas. As cozinheiras também são produtoras agroecológicas.

A Feirinha da Argentina, localizada na região central de Puerto Iguazú, funciona todos os dias da semana das 10:00 às 14:00 horas e das 16:00 às 23:00 horas. Situa-se a 350 metros do cruzamento mais famoso e movimentado da cidade.

Segundo o presidente da Associação da Feirinha, Batista (2019), a Feirinha cresceu em número de vendedores e de produtos e em volume de venda quando passou a fazer parte do pacote de agências turísticas do Brasil, devido aos produtos artesanais que vendia. Salientou, ainda, que eram produtos que não chegavam ao Brasil vindos da Argentina ou que eram muito caros do lado brasileiro.

A feira conta com 29 barracas que vendem produtos industrializados ou comidas prontas para serem consumidas no local. Essas barracas poderiam ser categorizadas como bares e restaurantes, pois possuem uma área com mesas e cadeiras, como uma praça de alimentação. A Feirinha da Argentina é uma feira com alma turística.

Os produtos prontos para o consumo identificados nestes bares e restaurantes são divididos em três categorias: picadas (tábua de frios), empanadas (pastéis) e dois tipos de carnes, picanha ou bife de chorizo. Evidencia-se a repetição das opções fornecidas pelos estabelecimentos.

Nas poucas barracas que comercializam apenas produtos industrializados argentinos, os produtos e as marcas se repetem, barraca pós barraca, entre azeitona, azeite de oliva, queijo, salame, vinho, alfajor, molho chimichurri, entre outros. Produtos que marcam a identidade argentina nesta feira e reforçam o apelo turístico.

Propusemos uma rota hipotética para visualização daqueles que não estão familiarizados com essas feiras e seus territórios. Chamamos de rota hipotética, pois as três feiras possuem horário e dia de funcionamento diversos. Entretanto, imaginemos sair da Feirinha da Argentina, rumo à Feirinha da $\mathrm{JK}$ e de lá sairmos com destino à Feria de Ciudad 
del Este. Saindo do primeiro ponto até a Feirinha da JK são 12,6 km; e entre a Feirinha da JK até a Feria de Ciudad del Este são mais 10,9 km. Ao todo tem-se $23,5 \mathrm{Km}$, passando por quatro aduanas, quatro estruturas de controle estatais, duas pontes - da Fraternidade e da Amizade - e dois rios - Iguaçu e Paraná. Chegando e parando em três locais, três feiras, três espaços de comidas diversas.

Figura 1 - Rota hipotética das três feiras ${ }^{8}$

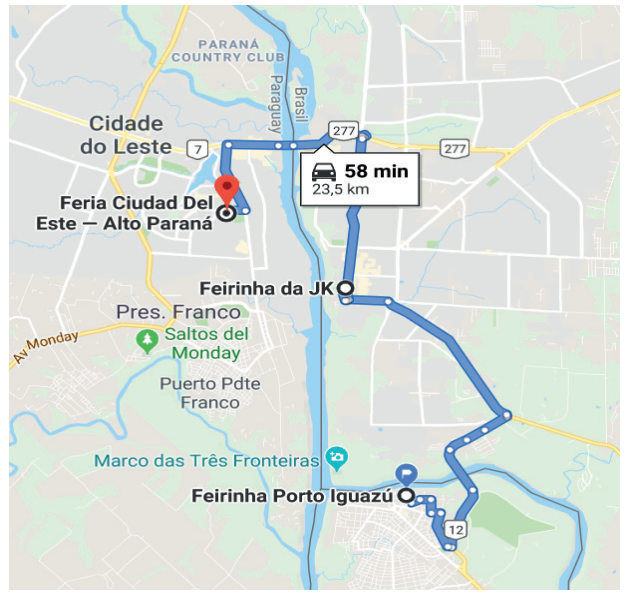

Fonte: Google Maps

São três feiras com características comerciais distintas, em territórios nacionais diferentes, separadas pelas aduanas, mas que no cotidiano se entrelaçam no território, nas interações e nas trocas. A localização de cada uma realça a definição dos discursos identitários, que são relacionais, situacionais e mostram a constante (re)construção das fronteiras entre os sujeitos nesses espaços, o que nos impele a refletir sobre fronteiras e identidades.

\section{FRONTEIRAS E IDENTIDADES}

Em uma perspectiva teórica, de acordo com Bourdieu (2001), a delimitação de fronteiras - tanto materiais, quanto simbólicas - são atos premeditados que pretendem delimitar e se fazer reconhecer frente ao outro. Entendemos as fronteiras como algo não fixo, mas moldado de acordo com as percepções e construções dos indivíduos que vivem em um espaço de interconexão sociocultural, econômica e territorial.

Reflete-se nesta pesquisa sobre as interconexões e as transposições de fronteiras, tanto físicas quanto simbólicas, nas práticas alimentares do cotidiano, uma vez que as fronteiras podem ser resultado das construções das memórias e identidades coletivas, que se amparam em definições de representações constituídas e entendidas como referenciais de coletivos frente ao outro.

Ao falar sobre identidade, a entendemos como móvel e plástica, a partir da lógica de pensamento de Barth (2000), que mostra que grupos 
étnicos não são predefinidos e não podem ser definidos. Entretanto, os grupos são entidades que surgem do processo de definição cultural, socialmente estabelecidos e subjetivamente percebidos, entre grupos que interatuam em um marco interétnico específico. É a interação entre grupos que estabelece dinâmicas complementares de competição, de dominação e também de inclusão, de acordo com a realidade sociocultural, econômica e política vivida. Dessa forma, entendemos que as identidades são construídas socialmente, a partir de experiências históricas da interação entre grupos fronteiriços (PUJADAS, 2011).

Tilley (2006) e Hall (2006) também argumentam sobre identidades nessa mesma perspectiva, entendendo-as como relacionais, situacionais e em constante movimento. Hall (2006) indica que a identidade é formada ao longo do tempo, sempre em processo, no qual o sujeito assume diferentes identidades em distintos momentos, de acordo com os diversos grupos dos quais participa. Não se fala, assim, em identidades fixas, mas sempre em movimento (TILLEY, 2006), o que denota observar as representações que as constituem dentro do tempo e do espaço que as circundam; e considerar o ambiente de múltiplas interações e construções em que a pesquisa se insere.

Nesse sentido, discutimos identidades coletivas - que segundo Candau (2011), resultam de jogos sutis produzidos nos quadros de relações, reações e interações sociais - das quais emergem o sentimento de pertencimento e geram fronteiras sociais. Assim sendo, a experiência compartilhada e a definição de representação podem constituir uma coletividade que compartilha da mesma identidade, definindo o "nós" e o "outro". E, ao se constituir um grupo, ocorre uma classificação e produção de diferença, isto é, fronteiras.

Assim como identidades não são fixas e homogêneas, tampouco as fronteiras o são. O limite fixo, a fronteira política, faz parte da construção dos Estados-nações modernos - comunidades imaginadas - onde se pressupõe a igualdade da população e o limite territorial bem definido, como aborda Anderson (2008). Contudo, a realidade vivida não corresponde a essa imagem criada sobre as nações. As inter-relações socioculturais fronteiriças e econômicas são constantes, os limites territoriais muitas vezes unem mais do que separam e as regiões internas que se pressupunham iguais são muito diferentes.

Dessa forma, abrimos a perspectiva analítica sobre a fronteira entre Brasil, Argentina e Paraguai não como definição de diferença, limite geográfico e cultural, mas como espaço de inter-relação constante, que responde aos contextos vividos, com estratégias de construção, de representações, de acordo com as experiências vividas e os interesses de cada momento.

Além dos usos estratégicos da fronteira - derivados das políticas estatais em cada momento histórico - deve ser considerado o papel desempenhado pelas populações fronteiriças, isto é, o conjunto de ha- 
bitantes localizados de cada lado da fronteira cuja vida diária gira em torno do fato da fronteira: agentes de controle e vigilância; moradores fronteiriços e trabalhadores que cruzam diariamente as pontes; as pessoas envolvidas no comércio internacional ou que procuram serviços médicos e de educação; e os visitantes e turistas que trafegam pelos espaços fronteiriços. A lógica da fronteira como um limite ou como uma parede de separação exclui a própria existência de regiões de fronteira, entendidas como espaços para reunião, intercâmbio, hibridação, miscigenação e conflito de interesses (PUJADAS, 2014).

Benedetti e Salizzi (2014) apontam que as zonas de fronteiras podem configurar uma região com características singulares. Lugares que são formados pelas relações entre as diferentes territorialidades que se sobrepõem em uma ideia de multiterritorialidade, em referência a Haesbaert (2004).

O estudioso de fronteiras e suas dinâmicas sociais Eric Cardin (2012, p. 208) utiliza termos gastronômicos para tecer considerações sobre esse assunto: "A fronteira se apresenta como um imenso caldeirão, de conteúdo denso e quente, onde borbulham interesses e temperos diferentes, onde os aromas se misturam, resultando em uma realidade ímpar". A fronteira é simbolizada por um caldeirão, um caldeirão de pessoas, profissionais, famílias, ideias, conceitos, preconceitos, costumes, tabus, legalidades, ilegalidades, práticas cotidianas, laços, deslaços, encontro e desencontro.

Deste modo, a fronteira é o rescaldo metafórico de um caldeirão forte, com sustância, às vezes amargo, outras salgado, algumas vezes azedo, e até - porque não - um caldeirão doce. Depende de quem o degusta, do que degusta, como degusta, quando degusta e com quem degusta.

Nestes espaços há pessoas - desde tempos imemoriais - que comem, bebem e transitam e, assim, não se deve negligenciar fronteiras, tampouco integrações ou reconfigurações fronteiriças, além das multiculturalidades e translocalidades. É um território complexo, no qual as relações de poder político, simbólico, econômico, social e cultural estão em constante disputa. Assim, apresentam-se diversos sistemas alimentares - em fricção, interação, adaptação - que nos permitem observar a multiplicidade de fronteiras e identidades que formam o caldeirão que caracteriza este território.

\section{COMIDAS FRONTEIRIÇAS}

Assim como as pessoas, comidas e ingredientes vêm e vão nestas fronteiras, às vezes com maior fluidez e leveza, e outras não tão espontaneamente assim. Para esta reflexão, apresentamos apontamentos a partir de falas dos entrevistados e da observação participante, que nos permitem visualizar as relações e os discursos estabelecidos nas feiras a partir do olhar para as fronteiras.

A imagem de uma Foz do Iguaçu multiétnica se apresenta na Feirinha da JK, entre as bancas, talvez sem querer, talvez por querer. Par- 
tindo da hipótese de que poderia ter sido intencional ou proposital a existência de várias bancas de imigrantes e migrantes representadas na Feirinha, foi questionado ao coordenador da feira, Ronaldo Pinheiro, sobre o tema.

Sobre os imigrantes que trabalham na Feirinha, Pinheiro (2019) atestou que se o estrangeiro está regular no país não há empecilho ou favorecimento para que ele possa trabalhar como feirante. O coordenador afirmou que atualmente há em torno de 10 famílias estrangeiras que trabalham na feira, porém reforçou que não há facilidade ou procura por parte da Fundação Cultural (órgão gestor) para que alguém, mesmo estrangeiro, participe da feira.

Ainda nesta temática de imigrantes, o coordenador acentuou que, constantemente, é procurado por paraguaios e argentinos interessados em participar da feira. Entretanto, eles não conseguem participar devido ao alvará de feirante. Para a obtenção do alvará, um dos pré-requisitos é ser residente na cidade. A questão da nacionalidade não importa, mas a residência, a documentação, sim. Trata-se de uma demarcação territorial tão precisa em uma região fronteiriça onde as fronteiras físicas ora são rígidas e ora são porosas. Esses imigrantes podem ir e vir, mas não podem comercializar. A feira que parece informal tem suas formalidades.

Com relação aos produtos de origem dos demais países fronteiriços, Pinheiro (2019) comenta sobre a proibição da comercialização de produtos do Paraguai, visto que "produtos importados não podem". Porém, o que não pode ser comercializado? Produtos importados ou produtos oriundos do Paraguai? E os produtos provenientes da Argentina? Pensamos que são as naturalizações deste espaço. Enquanto é comum a associação à ilegalidade dos produtos vindos do Paraguai, e por isso proibidos; os produtos argentinos sequer foram lembrados nesta conversa.

Verifica-se uma dinâmica paradoxal e ambígua, pois a fronteira admite oposição e diferenças - limita, mas igualmente concede passagem (WELTER, 2018), o que caracteriza uma miscelânea de aspectos e multiplicidade de conceitos que podem ser abarcados, privilegiados para a observação sociológica (MARTINS, 2009) que percorre redes e circuitos em uma trama que se dá por meio das relações sociais.

Pode-se supor que, por produtos do Paraguai, o entrevistado estava se referindo aos eletrônicos e outras "bugigangas" vindas do país vizinho; esta é uma expressão cotidiana da fronteira para se referir a este tipo de mercadoria. Contudo, expandimos essa discussão também para os produtos alimentares. Nota-se, assim, a construção de representações sobre o outro pautadas nas relações históricas e de poder entre os grupos.

Nesta feira, há duas barracas com produtos argentinos como doce de leite, alfajor, azeite de oliva, conservas, chimichurri e vinhos. Uma de um feirante brasileiro e a outra de uma simpática senhora uruguaia. 
Estes produtos, todos de marcas argentinas, inclusive as mesmas encontradas do outro lado da fronteira, nos dá a impressão, por alguns segundos, de que estamos em outra feirinha, a da Argentina. Em outras bancas também há produtos argentinos, porém misturados com outros produtos de marca nacional. Uma outra banca de brasileiros vende empanadas prontas e quentes apresentadas em uma estufa. Há ainda uma banca, de um brasileiro, que vende alfajor caseiro, com uma placa que diz receita argentina. Demarcações identitárias na comida.

Enquanto há produtos alimentares argentinos sendo vendidos, não há produtos reconhecidos como paraguaios. Apesar disso, em diálogos com feirantes, alguns contaram que compram produtos primários como temperos, algumas bases para as preparações e outros secos ${ }^{9} \mathrm{im}$ portados do Paraguai. Se as estratégias impostas pela instituição regem de uma maneira, no ato das práticas, os sujeitos, os produtores desconhecidos dão golpes e fazem bricolagens, como diria Certeau (2007). Transformam, de modo subversivo, uma matéria-prima proibida em algo comestível. Estas são práticas cotidianas: tanto a venda de produtos oriundos da Argentina como a venda de produtos compostos por ingredientes provenientes do Paraguai. A Argentina pode, mas o Paraguai não pode. São negociações simbólicas entre o Eu e o Outro, e o Eu com o Outro. Entre o brasileiro e o argentino, e o brasileiro e o paraguaio.

O trânsito de mercadorias - não necessariamente de produtos alimentícios - nas fronteiras é historicamente complexo. Nesta fronteira não é diferente. Respeitando as lógicas do mercado local e global alguns produtos têm trânsito legalmente liberado, enquanto outros não. Contudo, percebe-se que alguns produtos alimentícios, como os oriundos da Argentina, são coletivamente aceitos/normalizados nas práticas cotidianas, mesmo não sendo importados legalmente. Como se houvesse hierarquias de legalidade e um reconhecimento coletivo sobre isso.

Assim, alimentos que legalmente não poderiam circular, circulam, mais ou menos de acordo com os discursos preestabelecido e compartilhados sobre a sua "legalidade". Levanta-se a hipótese de que esse reconhecimento esteja relacionado com o poder simbólico de alguns alimentos frente a outros, reforçados pelos discursos turísticos, nos quais, por exemplo, se vende largamente a culinária/gastronomia argentina enquanto não se menciona a paraguaia. Nota-se assim, identidades e fronteiras em negociação e fricção - física e simbólica - refletidas nas práticas alimentares.

$\mathrm{Na}$ Feria de Ciudad del Este há frutas, verduras e hortaliças brasileiras provenientes da CEASA, competindo com os mesmos produtos hortigranjeiros produzidos pelos produtores agroecológicos da região do Alto Paraná, o que acarreta uma série de conflitos internos na feira. Esses conflitos estão presentes entre bancas e também nos jornais paraguaios, e esses comerciantes de produtos vindos da CEASA são denominados contrabandistas. Assim como produtor e comerciante, as 
palavras contrabando e contrabandista assumem novos significados do outro lado da fronteira. Não se trata só de eletrônicos, cigarros, drogas e armas. Comidas também podem ser contrabandeadas. São ressignificações. São outras fricções fronteiriças e identitárias.

$\mathrm{Na}$ Feirinha da Argentina fizemos o registro de uma farofa pronta industrializada de marca brasileira e do arroz, feijão e picanha nos cardápios de bares e restaurantes - pratos "brasileiros", o que caracteriza adaptações frente/para o Outro. Porém, a Argentina está demarcada ali, entre os produtos expostos nas prateleiras (alfajores, vinhos, azeitonas, doce de leite, dentre outros) e as comidas apresentadas nos cardápios (empanadas ou bife de chorizo). Exceto os casos acima mencionados, não há resquícios de uma diversidade de produtos de outras culturas, como ocorre na Feirinha da JK. A Argentina quer ser demarcada, quer ser comercializada, é a sua marca cultural/identitária que atrai os visitantes. Revelam-se construções de discursos identitários que ocorrem nas relações cotidianas.

São comidas fronteiriças, comidas que vêm e vão entre pontes, comidas que andam com os pés de pessoas fronteiriças, comidas poliglotas que se comunicam em outras línguas, nem que seja o "portunhol".

Os vestígios alimentares aqui relatados e encontrados nas feiras não se limitam a estes espaços, mas são reflexos dos sistemas alimentares encontrados neste território. As pessoas e as comidas dos três lados também circulam nos corredores e nas prateleiras de supermercados, hipermercados, atacadistas, empórios e até em lojas de especialidades nacionais ou regionais. Argentinos daqui, paraguaios dali, brasileiros acolá, entrelaçados por uma incontável diversidade de origens. Sujeitos fronteiriços que circulam, andam e transitam por este território dependendo do câmbio, do interesse e do gosto. Essas relações permitem observar as interações, fricções, re-construções de identidades e valores que se estabelecem nesse território.

\section{COMIDAS E MIGRAÇÕES}

Pessoas também andam, vêm e vão. Pessoas carregam coisas, nas mãos, nos estômagos ou nas memórias. Entre estas coisas estão as comidas. Nota-se, na Feirinha da JK, bancas de imigrantes e migrantes vendendo comidas que têm relação com a sua origem, com marcações identitárias bem estabelecidas. Essas marcações são evidenciadas por meio de banners ou cartazes de identificação na frente das bancas, realçando a representação de origem, nacional ou regional ali presente; não é uma suposição, é uma constatação.

Focaliza-se especificamente a Feirinha da JK neste subitem, baseando-se nos indícios e nas características desta feira, pois na Feria de Ciudad del Este os trabalhadores são paraguaios, exceto por um ou outro brasiguaio $^{10}$ e na Feirinha da Argentina os trabalhadores são argentinos, com exceção de uma venezuelana que o coordenador da feira reiterou que é naturalizada argentina. 
A comida pode ser considerada um fator identitário, um demarcador de fronteiras entre o Eu e o Outro. Rocha, Rial e Hellebrandt (2013) enfatizam a alimentação em sua dimensão simbólica, como um item essencial de identificação dos migrantes com sua cultura de origem e, ao mesmo tempo, da negociação com a cultura em que se inserem. Nestas abordagens, a comida pode ser o elo e/ou a fronteira entre o novo e o velho. Seja por resistência identitária, seja como forma de adaptação à nova realidade, a alimentação pode ser um meio de identificação dos migrantes relativos às suas origens e demonstra disposição na negociação com a nova cultura.

Os antropólogos Contreras e Gracia (2011) enfatizam que as cozinhas refletem as sociedades: "Cada grupo social possui um quadro de referências que guia a escolha de seus alimentos. Algumas dessas referências são compartilhadas com outros grupos, outras são exclusivas" (CONTRERAS; GRACIA, 2011, p. 139). Esta afirmação não significa que os comportamentos alimentares se mantiveram estáticos e não sofreram alterações em suas sociedades e seus respectivos territórios.

Di Renzo (2019) compara a cozinha a uma caixa-preta da sociedade, referindo-se ao equipamento encontrado nos aviões que armazena e registra vozes e dados dos voos. Na cozinha, portanto, estariam contidos esses registros de gostos e de significados que as pessoas ativam quando compram, preparam ou consomem as comidas. Ela armazena as mudanças no tempo e no espaço dos sistemas mentais que abarcam ideologias, tabus, religiosidades, fobias, economias, entre tantos outros.

Com base nesses autores, propomos que a cozinha, ou seja, a cultura alimentar, é algo simbólico, em que os ingredientes devem ser percebidos para além das características nutricionais, funcionais e organolépticas; e as práticas, contempladas para além dos processos mecânicos e automáticos. Ingredientes e práticas devem ser articulados no social, no cultural, na história e com seus praticantes.

A comercialização de comidas típicas reforça a relação entre o imigrante e/ou migrante e o trabalho que exerce, à medida que ele cria seu posto de trabalho usando comidas tradicionais de seu país ou região e colhe dali - parcial ou totalmente - a sua fonte de renda. Reforçam-se os vínculos de continuidade com a origem e ao mesmo tempo se constroem laços com o novo território.

$\mathrm{Na}$ relação migrante, trabalho e comida são encontrados fatores como diversidade cultural alimentar, adaptações, hábitos e consumos que se entrelaçam com deslocamentos, memórias, comensalidade.

A banca japonesa com um casal de japoneses vende o tradicional takoyaki, bolinho assado japonês recheado com camarão, lula, carne ou misto, guioza e sushi, acompanhados de chá verde ou chá de hibisco.

Uma barraca chinesa oferece algumas iguarias deste país e outras "não tão chinesas", como rolinho primavera, tempurá, bubble waffle ou egg waffle, taiyaki, crepe francês, pastel frito e tapioca. Das bebidas, há 
chá e diversas variedades de bubble tea (chá verde, chá verde com gengibre e chá de hibisco com canela), além de suco de laranja natural. $\mathrm{Na}$ barraca, há um casal de chineses de Hong Kong e duas filhas. O casal quase não fala português e se dedicam ao preparo dos produtos. Uma das filhas que fala português fica no caixa, enquanto a outra ajuda na elaboração dos pedidos.

Em uma mesa improvisada, um jovem rapaz venezuelano, estudante da UNILA, ${ }^{11}$ vende a chicha, bebida ancestral indígena. A chicha apresentada na Feirinha da JK é feita à base de arroz e leva em sua preparação açúcar, cravo e canela. A bebida tem sabor semelhante ao arroz-doce. Porém, como a preparação é batida no liquidificador, resulta em uma espécie de arroz-doce líquido e espesso.

Em outra barraca, dois jovens taiwaneses propõem mais uma novidade para a Feirinha: o sushi vegano, composto de carne de soja, pepino e queijo de soja. Além dessa novidade, na barraca também podem ser encontrados rolinhos primavera tradicionais e veganos. Eles oferecem um suco de abacaxi natural. Na térmica desta bebida há uma série de explicações nutricionais e funcionais sobre os benefícios do suco natural de abacaxi adoçado com açúcar orgânico.

Nessa linha de bancas com produtos típicos pode-se mencionar ainda uma barraca com produtos italianos, Mama Mia Pastas D'Itália, com lasanhas, tortei, raviolli, tortellini, capeleti, rondelli, canelone e sofiotti, cujos proprietários pareciam ser descendentes de italianos, mas eram descendentes de alemães. Há outras duas bancas que vendem massas, a Massa do Nono e a Ivone Massas Caseiras. As massas estão na feira apenas para levar, pois não há degustação no local.

Há uma barraca de um casal mineiro que vende apenas o pão de queijo com fornadas que saem do forno truck. O que nos chama atenção na barraca é o slogan em letras garrafais "Pão de queijo: O autêntico Imitado sim, igualado jamais”. Mais uma vez verifica-se reforços identitários e de pertencimento através da comida.

A barraca de produtos pernambucanos é singular: lá se encontram manteiga de garrafa, queijo coalho, bolo de rolo, castanha de caju, bolacha de bolo de rolo, bolacha maragogi, feijão-de-corda, melaço de cana, doces em calda (caju, jaca, goiaba, coco), queijo de manteiga, carne de sol, carne de siri, caranguejo, lagosta, camarão seco e salgado e até linguiça e buchada de bode, esta última vendida apenas sob encomenda ao casal pernambucano. Quem ali habita sabe o quanto é difícil encontrar a maioria dos produtos elencados. São particularidades regionais que, nacionalmente, não são tão difundidas.

Na barraca Pamonha sabor goiano um casal de senhores goianos - que se mudou para Foz do Iguaçu para acompanhar o filho que foi estudar medicina no Paraguai ${ }^{12}$, vende pamonha doce, pamonha salgada e até pamonha frita, curau, bolo de milho e bolo de mandioca. Segundo Fernandes (2007), a pamonha possui raízes indígenas. Apesar 
de ser consumida em todas as regiões do Brasil, é em Goiás que recebe uma verdadeira homenagem, sendo considerada a marca registrada deste estado. Os clientes dessa barraca são moradores locais, mas também goianos que moram em Foz do Iguaçu, como pudemos verificar ao acompanharmos algumas interações de goianos comprando na banca.

Há uma barraca gaúcha que vende salame, linguicinha, bolachas e pão de milho. Os feirantes são um casal gaúcho. A banca se chama + Bah $T c h \hat{e}^{13}$, expressão marcante dos gaúchos, o que aponta a importância da demarcação de identidades nas comidas e também na língua.

Dentre todas as possibilidades de migrantes, destacamos as cinco bancas a seguir: a banca de Hong Kong, de Taiwan, a árabe, a mineira e a baiana.

A barraca de Hong Kong denominada Rei do Yakisoba é gerida por um casal de chineses. Eles vendem 21 pratos, como rolinho primavera, shumai de camarão ou de porco, sopa wandom, bifum (macarrão de arroz), pão chinês no vapor, guioza e até pé de galinha com feijão preto e costelinha ao vapor com arroz apimentado. Além, claro, de diversas versões de yakisoba.

Segundo Yu (2018, p. 93), os produtos comercializados pelo feirante são: “[...] tipicamente consumidos no café da manhã de Hong Kong, o chamado / dim sum/ (pronúncia em cantonês)”. As comidas são expostas em recipientes de alumínio que se encaixam uns sobre os outros. O que é registrado na barraca de Hong Kong é a moderna versão dos recipientes de bambu a vapor.

Ressalta-se que essa banca é a única na Feirinha da JK que oferece opção tanto de garfo e faca quanto hashi ${ }^{14}$. No restante das barracas, se come com as mãos. Aliás, sobre as mesas há hashi descartável, guardanapo, molho de pimenta e shoyo. Caso o cliente deseje faca e garfo, é preciso pedir. Ali o território é deles. Nós somos os Outros.

Enquanto o dim sum é café da manhã para os chineses, para os brasileiros é sinônimo de almoço. Essa diferenciação é nítida quando se observa horário versus consumidores. A maioria dos brasileiros chega à barraca perto da hora do almoço, enquanto os chineses estão ali desde o início da manhã. Cada qual com a sua leitura daqueles alimentos. Percebe-se uma ressignificação do que é considerado apropriado para cada refeição. O mecanismo inconsciente do que é considerado comida, do café da manhã, almoço ou jantar, é acionado pelo fator social e cultural. Hábitos e costumes diversos, mesmo que em horários distintos, se entrelaçam.

$\mathrm{Na}$ banca de Taiwan vende-se tortinha de Taiwan (com recheio de feijão doce, creme, amendoim, queijo e milho) e bubble tea (de chá preto, chá verde e chá verde com lichia). A tortinha é feita em um tacho específico importado do país. Aliás, também há ingredientes que chegam de lá.

Esta banca está há dez anos na Feirinha da JK e é gerida por pai, mãe e filhas, todos taiwaneses. Observa-se que marido e mulher não falam 
português, ficando a comunicação e a venda com as duas filhas que falam o idioma. A mãe faz as tortinhas, uma das filhas serve o chá, a outra fica no caixa, enquanto o pai observa no fundo da banca a movimentação e auxilia a quem for necessário.

Antes da imigração, o casal também fazia feira em Taiwan, comercializando os mesmos dois produtos: a tortinha e o bubble tea. Ao se estabelecerem no Brasil, algumas modificações foram realizadas. Uma das filhas nos conta que por adaptação ao público brasileiro eles adicionaram a opção de recheio de milho e queijo.

Modificações também foram encontradas em outra barraca - a barraca árabe - com a exclusão da carne moída nas receitas da esfiha de batata e do kibe de batata com coalhada, objetivando atender um público específico: os veganos e os vegetarianos. Estas alterações evidenciam a necessidade de adaptação dos imigrantes às novas relações sociais, costumes e novos hábitos alimentares (HECK; BELLUZZO, 1998).

Outra forma de adaptação frente ao outro foi verificada em entrevista com o coordenador da Feirinha da Argentina, Batista, que narrou:

Nós tivemos que criar uma gastronomia totalmente distinta, é possível ver que a picanha não é igual, os pastéis [empanadas] não são iguais, tivemos que adaptar tudo ao paladar brasileiro, paraguaio, estrangeiro. Então criamos uma gastronomia distinta do que se vê no resto da Argentina (BATISTA, 2019).

"Criaram" uma gastronomia distinta do que se considera como gastronomia argentina no restante do país. A invenção das tradições de Hobsbawm (2002) se aplica neste caso. É interessante frisar que o brasileiro e o paraguaio nestes discursos não são o estrangeiro. As fronteiras são relativizadas e fluídas. Há brasileiros, paraguaios e estrangeiros. E ele continuou: "Então serve para todos, pois criamos algo gostoso que agrada toda a gente, algo globalizado". Provocamos: "Fronteiriço?" Ele concordou: "Sim, é fronteiriço. Sim, é uma gastronomia da tríplice fronteira”.

A comida, bem como outras questões sociais, não é estática; está em constante transformação no tempo e no espaço. A tortinha de Taiwan não é mais a mesma, a esfiha não é mais a mesma, nem mesmo a empanada é a mesma. As comidas se adaptam, mudam e se transformam, dependendo dos diálogos que as pessoas que produzem e consomem estão dispostas a fazer.

Observa-se, igualmente, que muito além de nutrir, a comida se reveste de múltiplas, complexas e polivalentes funções, imersa em uma dimensão simbólica e emotiva, constantemente debatida entre passado e presente, tradição e mudança (CIVIDINI; STEFANUTTI; GREGORY, 2017).

Uma das faces desta dimensão simbólica é o deslocamento em prol da comida, dos seus sabores, das suas representações, das suas memórias e do encontro com os seus. Essa questão pode ser observada na banca de 
Taiwan, onde se forma uma roda de taiwaneses no entorno da barraca todos os domingos pela manhã. Segundo uma das feirantes, os taiwaneses habitantes de Ciudad del Este atravessam a Ponte da Amizade e vão à feira para comer sua comida típica. A comida se torna um meio para o encontro, para a manutenção da sociabilidade, a comensalidade.

Montanari (2008) aponta que a comensalidade, é o "com quem se come”. O comer em conjunto é típico do ser humano e é o momento em que "substância e circunstância assumem, ambas, um valor significativo, habitualmente coligadas uma a uma” (MONTANARI, 2008, p. 158). O compartir à mesa ou à feira é sinônimo de pertencimento ao grupo. Se reconstrói a identidade coletiva, reforçando os vínculos e também as diferenças, o "Eu" e o "Outro", mesmo em um território diverso, múltiplo e em constante transformação.

Contreras e Gracia (2011, p. 269) evidenciam que: "A percepção do ato de comer está intrinsecamente ligada a 'comer com'... (família, casal, filhos, amigos, adultos etc)". A comensalidade foi verificada no compartilhamento da comida, da mordida, do gole, do momento e da feira. A feira também é esse espaço onde comidas são degustadas e são partilhadas.

A próxima barraca a ser mencionada é a mineira, gerida por um jovem casal de Minas Gerais cuja esposa foi estudar medicina no Paraguai e o marido se mudou para a cidade acompanhando-a. Na barraca há doces, requeijão de corte, manteiga com sal, queijo minas padrão, queijo minas padrão zero lactose, queijo provolone recheado com lombo defumado e queijo Canastra. Todos os produtos são produzidos por parentes do casal no município mineiro de São Roque de Minas.

Esta feira representa as dinâmicas deste território fronteiriço, em que novas territorialidades são criadas a partir de novos fluxos populacionais ocorridos no tempo e no espaço. Essas novas territorialidades são marcadas pelas práticas alimentares que circulam por essas bandas, demonstrando, desta forma, que os sistemas alimentares são abertos e ocorrem no presente, a partir dos sujeitos e das possibilidades de circulação e fixação neste território.

Sobre o queijo Canastra, o casal conta que é o queijo mais famoso da região mineira, sendo o produto que as pessoas reconhecem logo à primeira vista. Na barraca, também é possível ver e ter seu café moído na hora, o que é uma atratividade visual e aromática do espaço, parte do universo de práticas alimentares que podem ser experienciadas em ambiente de feira.

Segundo o casal, os principais clientes são moradores de Foz do Iguaçu que são mineiros ou filhos de mineiros. "Às vezes eles compram para a mãe, para o pai, para a avó que são mineiros. Aqui na cidade tem bastante mineiro". Este discurso revela a perpetuação da memória e da identidade cultural através da comida.

Há uma barraca, mais afastada, que vende acarajé e seus tradicionais acompanhamentos: vatapá, caruru e camarão seco, servidos por uma 
baiana com suas vestimentas simbólicas, brancas, acompanhada de seu filho. No banner de divulgação há a foto do Pelourinho com baianas e suas vestimentas à frente e os dizeres: Acarajé da Ana: O sabor da Bahia agora em Foz! A fotografia foi feita pelo filho da feirante. Na ocasião ela não estava com a vestimenta simbólica. Usava uma camisa da própria barraca. Tempos depois, a vimos bater a massa de feijão fradinho na panela de alumínio com uma longa colher de pau. Quanto mais batido, mais aerado e leve o produto final ficará. Práticas e saberes.

A feirante soteropolitana, que desde $2013 \mathrm{faz}$ acarajé na feirinha da JK, nos conta que não fazia acarajé na Bahia porque lá já tinha uma grande quantidade de pessoas que ofereciam o produto. Segundo a feirante, anteriormente, ela tinha um "trabalho normal". Depois que se mudou para Foz do Iguaçu, percebeu uma oportunidade em oferecer o produto. Ela lembra que há um restaurante na cidade de cozinha baiana e somente ali era possível encontrar o acarajé, mas não como comida de rua, que é uma das marcas do ofício das baianas de acarajép ${ }^{15}$.

A feirante reforça que traz os ingredientes de Salvador, pois não os encontra em Foz do Iguaçu. Os ingredientes que vêm direto de Salvador para suas mãos são o azeite de dendê, o feijão fradinho e o camarão seco. Para a feirante, o acarajé é a cultura da Bahia. A feirante conta que não houve nenhum processo de alteração do acarajé para ser comercializado na Feirinha da JK, porém, disse que o abará ela só faz por encomenda, porque as pessoas ainda não se adaptaram, então ela faz para quem gosta.

O público da barraca está dividido entre baianos que moram em Foz do Iguaçu e pessoas da cidade que têm curiosidade de provar acarajé. Dos baianos que moram na cidade, ela diz que houve um aumento nos últimos anos em decorrência da mudança para a cidade para cursar medicina no Paraguai.

É interessante observar que a barraca fica distante das outras. Segundo o filho da baiana, os feirantes reclamaram do cheiro do azeite de dendê. Não só o sabor da Bahia está em Foz; o cheiro também. A comida e os sentidos tanto separam quanto agregam. Observam-se produtos, pessoas, identidades e fronteiras.

Contreras e Gracia (2011) compreendem a alimentação e suas relações como "marcadores étnicos", no sentido de elemento promotor de identidade, por meio da diferença. Os antropólogos afirmam que as diferenças alimentares e culinárias podem ser positivas, causar curiosidade e serem valorizadas - principalmente em um cenário contrário à homogeneização alimentar, e paradoxalmente podem ser negativas e causar estranhamento, estigmatização e preconceito. Depende das negociações e das relações de poder que também permeiam as questões alimentares e, neste caso, o acarajé.

Cascudo (2011) reforça a importância da questão olfativa na formação do gosto. Cheiro bom ou cheiro ruim também são ativados no social. Aceitação ou repulsa são fatores culturais. O cheiro do azeite de 
dendê na Feirinha da JK traz incômodo para alguns feirantes e alegria para alguns clientes. São cheiros que atraem e repulsam. Trata-se do mesmo cheiro, das mesmas partículas voláteis que são recebidas pelos órgãos olfativos e produzem sensações diversas. Reforça-se assim que tanto o cheiro quanto o gosto são construções culturais e simbólicas, e não apenas experiências individuais.

Na barraca árabe, denominada 7 Temperos - Culinária Árabe $e^{16}$, há esfiha de carne, batata e chicória, falafel e kibe frito recheado com coalhada. Os produtos são vendidos por uma feirante árabe usando lenço (hijab) e sua filha, que não utiliza este acessório identitário. Ao longo da pesquisa aprendemos que a feirante é brasileira, nascida no Rio Grande do Sul, e seus pais são libaneses.

Ela conta que o fato de utilizar o hijab faz uma grande diferença em relação à percepção do público, tendo escutado várias vezes: "Agora vou comer uma esfiha ou um kibe de verdade". O hijab em sua cabeça e colo representa a autenticidade imaginada que suas mãos possuem. Ela ressalta, porém, que não é por esse motivo que utiliza o adereço. Percebe-se que as roupas ou seus adereços, como a árabe e/ou a baiana, fazem parte do discurso identitário e reforçam as diferenças e os pertencimentos, mesmo nas relações alimentares.

Sobre os produtos ela diz que tem vários produtos que vêm de lá [Líbano]. A feirante relata que é comum pedir para amigos ou familiares que estejam em viagem para que no retorno tragam um tempero ou algum produto específico. Ela diz que esse costume tem uma relação econômica, mas também pode ser interpretado como uma relação com o produto de origem, que veio de determinado território, e que carrega memórias, histórias e simbologias.

A feirante diz que os produtos que comercializa na barraca são tradicionais e são preparados como sua mãe, avó e tia fazem, sendo este conhecimento transmitido por gerações.

Houve um relato interessante sobre doces árabes. Ela conta que quando começou na feira havia uma outra barraca árabe que comercializava apenas doces árabes. O feirante era um refugiado sírio que era doceiro profissional na Síria. Ele passou a revender alguns doces para ela, até que ele se mudou para Goiás. Porém, antes da viagem, ele foi até a casa dela e a ensinou a fazer os doces árabes. "Então os doces que eu faço hoje, foi esse senhor, esse doceiro profissional sírio, que me ensinou”. Os doces são as bolachas com tâmaras e as bolachas de gergelim. Verifica-se uma transmissão de saberes entre a própria comunidade.

Diferente do que ocorre nas outras bancas, seu público são moradores e turistas, e muito pouco da comunidade árabe. A feirante menciona que nunca foi o objetivo vender para este público e que: "[...] eu nasci, fui criada na comunidade com os costumes de lá. Quando eu quero sair, a única coisa que eu não quero comer é comer comida árabe, é kibe e esfiha. Eu vou querer comer uma comida diferente". Ela tem encomen- 
das de árabes de kibe frito congelado e de bolachas de gergelim e de tâmaras. "Afinal, todo mundo faz esfiha em casa, né?".

A comercialização de alimentos nos casos mencionados são formas de complemento de renda destas famílias, sendo considerado uma estratégia de sobrevivência destes feirantes e produtores.

Há outras barracas de comidas de feira que não se aportam em representações identitárias nacionais ou regionais como a venda de pastel, coxinha, tapioca, pão de queijo, espetinho, açaí, bolinho de peixe, crepe francês e crepe suíço, além de caldo de cana, sucos naturais e água de coco aberto na hora. Apesar de vários desses exemplos poderem ser associados a determinados territórios, eles não foram identificados como tal pelos próprios feirantes ou em signos nas barracas, que é o caso da tapioca, do açaí e dos crepes. Assim, a identidade nacional ou regional é utilizada por alguns feirantes, mas não por todos, destacando a multiplicidade do território e das formas de se vivenciá-lo.

Ao pesquisar a partir de feiras, observar o cotidiano e seus detalhes, pode-se refletir sobre as dinâmicas, negociações e estratégias de pessoas que vêm e vão no espaço, modificando-o por meio de suas práticas alimentares. A comida pode ser novidade, atratividade visual e aromática; pode representar autenticidade; pode marcar fronteiras entre o Eu e o Outro; mas, igualmente, adaptar-se para agradar paladares diversos e ser veículo de transmissão de saberes entre a própria comunidade. Diversas (re)territorialidades foram observadas, seja como estratégia de sobrevivência ou complemento de renda, com a perpetuação da memória e identidade cultural através da comida ou ainda a disposição de negociar com uma nova cultura.

Assim, além de nutrir, a comida também é encontro, auxilia na manutenção da sociabilidade, do pertencimento ao grupo, marca fronteiras, ao mesmo tempo que as rompe, que as transpõe. Reconstrói, ressignifica e difunde sua identidade por meio da culinária. Retrata a experiência histórica, sua diversidade populacional, e a inter-relação do território estudado. É transnacional - com interações, fricções, adaptações, em que cada migrante (trans)forma a territorialidade fronteiriça com seus sabores.

\section{CONSIDERAÇÕES FINAIS}

Takoyaki, sopa paraguaia e bife de chorizo são exemplos de comidas fronteiriças encontradas nestas feiras. Por meio delas, pode-se verificar a Feirinha da JK como um espaço com comidas regionais e de nacionalidades diversas, nas quais migrantes fazem adaptações frente aos novos ingredientes e novos públicos, ao mesmo tempo que mantêm seus vínculos com sua origem. Na Feria de Ciudad del Este, as chamadas comidas de feira são comidas do cotidiano nas mesas paraguaias e representam uma luta do campesinato paraguaio, sendo uma comida da terra, de paraguaios para paraguaios, fechadas em si mesmas, com 
base em produtos agroecológicos. Na Feirinha da Argentina, verifica-se a comida fronteiriça turística adaptada para atingir aqueles que são de fora. Comidas e tradições criadas mas que mantêm o vínculo com uma identidade definida. Tem-se, assim, diferentes tipos e vivências de feiras, com suas múltiplas identidades e fronteiras, que refletem as relações de poder estabelecidas neste território.

Esses indícios alimentares levantados nas feiras são parte da história, da memória, da transmissão de saberes e fazeres, das práticas cotidianas, dos sistemas e das culturas alimentares deste território. Portanto, pode-se dizer que estes vestígios são parte constituinte do patrimônio alimentar local, muito mais do que Pirá de Foz ou Dourado Assado.

Concordamos com Montanari (2008, p. 189-190), que afirma: “[...] as culturas alimentares (e as culturas em geral) são mais ricas e interessantes quanto mais os encontros e as trocas tenham sido vivazes e frequentes - por exemplo, nas situações de fronteira”. Foi possível verificar como são ricas e singulares essas interações, trocas, idas e vindas de pessoas, mercadorias e saberes em um contexto fronteiriço.

A feira não é estática. Ela é orgânica e está em constante transformação. Ela acompanha fluxos migratórios, dos antigos aos mais atuais, como o último, ocasionado pelos estudantes de medicina no Paraguai, que moram em Foz do Iguaçu; as reivindicações por espaços de escoamento da produção agroecológica em Ciudad del Este; e os interesses turísticos em Puerto Iguazú. As feiras e os sistemas alimentares apresentados acompanham as dinâmicas e as movimentações do território. Os sistemas alimentares são complexos, abertos e ocorrem no presente, no espaço que o circunda e respondendo às experiências e expectativas dos grupos que os acionam identitariamente.

Assim, mercadorias, comidas, pessoas e saberes vêm e vão entre as fronteiras. Levam consigo suas características identitárias e transformam o território com seus sabores, cheiros, cores, em um processo de multiterritorialidade. A alimentação é mais um fenômeno social suscetível às dinâmicas, interações, influências e singularidades que o estar e viver na fronteira pode possibilitar. A "fotografia" desse território não é fixa, as comidas mudam de acordo com a mobilidade dos sujeitos e as possibilidades de trânsito, e assim as fronteiras também se transformam, em um constante jogo de poder e representação.

Compreendemos as culturas alimentares fronteiriças por meio das feiras não como algo finalizado e cristalizado, tampouco como unânime, mas como algo sendo construído no cotidiano, que possui vestígios indígenas, migrantes (de longe e de perto) e turísticos; indícios agroecológicos e da monocultura; traços de diversidade e de continuidade, tudo isso envolto em práticas, saberes e ingredientes que vêm e vão neste contexto de fronteiras. Afinal, a cultura alimentar é a comida praticada. 


\section{NOTAS}

1. Segundo dados do Estudo da Demanda Turística Internacional realizado em 2018 pelo Ministério do Turismo, Foz do Iguaçu é o $3^{\circ}$ destino mais visitado por turistas internacionais na categoria Lazer, Negócios, Eventos e Convenções. Ver mais em: BRASIL. Ministério do Turismo. Estudo da Demanda Turística Internacional - Brasil - 2018. Disponível em: <http://www.dadosefatos. turismo.gov.br/> . Acesso em: 07 nov. 2020.

2. Segundo a Dirección General de Estadística, Encuestas y Censos (2015), Assunção possui 529.433 habitantes e Ciudad del Este 281.422 habitantes. Segundo o mesmo órgão governamental, Assunção contabilizou em 2011 o ingresso de receitas na ordem de 97 trilhões de guaranis e Ciudad del Este cerca de 32 trilhões de guaranis. Ver mais em: DIRECCIÓN GENERAL DE ESTADÍSTICA, ENCUESTAS Y CENSOS. 2015. Disponível em: <http://www.dgeec.gov. py/>. Acesso em: 07 nov. 2020.

3. Puerto Iguazú é uma cidade pequena e, portanto, não possui extrema relevância para a economia Argentina. Porém, as três cidades juntas formam uma grande rede de infraestrutura turística.

4. Ver mais em: FOZ DO IGUAÇU. Pratos Típicos. Disponível em: <http:// www.pmfi.pr.gov.br/turismo/\%3Bjsessionid\%3D3797854c4e16d0c8125784fb62c4?idMenu=1698>. Acesso em: 12 ago. 2019.

5. Ver mais em: FOZ DO IGUAÇU. Agência de Notícias Governo Municipal de Foz do Iguaçu. Projeto Feira Livre das Nações. Disponível em: <http://www. pmfi.pr.gov.br/noticia/?idNoticia=36904>. Acesso em: 13 abr. 2019.

6. Mercados com duas principais características: venda direta - quem produz é quem vende - e produtos à quilômetro zero, isto é, venda de produtos do próprio território, sem grandes deslocamentos. Do próprio território entende-se por região, ou no Paraguai por departamento.

7. Ver mais em: ADN PARAGUAYO. Feriantes están en contra de comerciantes que venden productos de contrabando. ADN Paraguayo, Ciudad del Este, 11 set. 2018. Disponível em: <http://www.adndigital.com.py/feriantes-estan-comerciantes-venden-productos-contrabando/>. Acesso em: 17 abr. 2019.

8. Ver mais em: GOOGLE. Google Maps. Disponível em: <https://www.google. com.br/maps/>. Acesso em: 21 abr. 2019.

9. Se houvesse a identificação dos produtos, a ligação com a barraca seria imediata, por isso optou-se pela não descrição de quais produtos são adquiridos no Paraguai.

10. Segundo Albuquerque (2009), os brasileiros que residem no Paraguai são geralmente conhecidos como "brasiguaios" e este termo poderia ser entendido como uma identificação fronteiriça híbrida. Porém, com o tempo, "o termo adquiriu sentidos variados, funcionando como uma identificação ambígua, situacional e negociada conforme os interesses que necessitavam ser explicitados ou ocultados" (ALBUQUERQUE, 2009, p. 154).

11. Universidade Federal da Integração Latino-Americana.

12. Tem havido um interesse crescente por brasileiros, de norte a sul do país, para estudar medicina no Paraguai, pois as faculdades privadas paraguaias praticam mensalidades bem abaixo dos preços praticados no Brasil. No início de 2020, só em Ciudad del Este foi registrada a marca de 20 mil estudantes. Porém, muitos destes estudantes optam por somente estudar no município paraguaio 
e moram, comem e vivem do lado da fronteira brasileira. Os estudantes e seus acompanhantes aparecem tanto do lado de dentro, quanto do lado de fora das barracas. Mais informações sobre o crescente número de estudantes de medicina no Paraguai ver: PORTAL DA CIDADE. Sem previsão de retorno das aulas, estudantes de medicina deixam o Paraguai. Portal da Cidade, Foz do Iguaçu, 24 abr. 2020. Disponível em: <https://foz.portaldacidade.com/noticias/regiao/ sem-previsao-de-retorno-das-aulas-estudantes-de-medicina-deixam-o-paraguai-1453>. Acesso em: 07 nov. 2020.

13. "Mas bah tchê" é uma interjeição gaúcha.

14. Hashi: par de palitos utilizado pelos orientais como talher. O presente nesta na feira é de bambu e descartável.

15. O Ofício das Baianas de Acarajé está escrito no Livro de Registro dos Saberes e foi considerado Patrimônio Cultural do Brasil pelo IPHAN em 2004 (IPHAN, 2007).

16. O logo da banca tem traços árabes como os famosos arabescos.

\section{REFERÊNCIAS}

ADN PARAGUAYO. Feriantes están en contra de comerciantes que venden productos de contrabando. ADN Paraguayo, Ciudad del Este, 11 set. 2018. Disponível em: <http://www.adndigital.com.py/ feriantes-estan-comerciantes-venden-productos-contrabando/>. Acesso em: 17 abr. 2019.

ALBUQUERQUE, José Lindomar C. A dinâmica das fronteiras: deslocamento e circulação dos "brasiguaios" entre os limites nacionais. Horizontes Antropológicos, Porto Alegre, v. 15, n. 31, p. 137-166, 2009.

ANDERSON, Benedict. Comunidades Imaginadas. São Paulo: Companhia das Letras, 2008.

BARTH, Fredrik. O guru, o iniciador e outras variações antropológicas. Tradução de John Cunha Comeford. Rio de Janeiro: Contra Capa, 2000.

BATISTA, Julio César. Entrevista concedida em 18/04/2019 às autoras, em Puerto Iguazú.

BENEDETTI, Alejandro; SALIZZI, Esteban. Fronteras en la construcción del territorio argentino. Cuadernos de Geografía: Revista Colombiana de Geografía, v. 23, n. 2, p. 121-138, 2014.

BENITES, Luis Lopes. Entrevista concedida em 03/04/2019 às autoras, em Ciudad del Este.

BIANCHIN, Aracelli. A dinâmica territorial na fronteira trinacional do iguaçu pelo turismo: integração ou fragmentação? Dissertação (Mestrado) - Universidade Federal da Integração Latino Americana, Foz do Iguaçu, 2018.

BOURDIEU, Pierre. O poder simbólico. 4 ed. Rio de Janeiro: Beltrand Brasil, 2001.

BRASIL. Ministério do Turismo. Estudo da Demanda Turística Internacional - Brasil - 2018. Disponível em: <http://www.dadosefatos. turismo.gov.br/>. Acesso em: 07 nov. 2020. 
CANDAU, Joel. Memória e Identidade. São Paulo: Contexto, 2011.

CARDIN, Eric Gustavo. Trabalho e práticas de contrabando na fronteira do Brasil com o Paraguai. Revista Geopolítica(s), v. 3, n. 2, p. 207-234, 2012.

CASCUDO, Luís da Câmara. História da Alimentação no Brasil. 4 ed. São Paulo: Global, 2011.

CERTEAU, Michel de. A invenção do cotidiano 1: artes de fazer. Tradução: Ephraim Ferreira Alves. 13 ed. Petrópolis: Vozes, 2007.

CERTEAU, Michel de; GIARD, Luce; MAYOL, Pierre. A invenção do cotidiano 2: morar, cozinhar. Tradução: Ephraim Ferreira Alves e Lúcia Endlich Orth. 7 ed. Petrópolis: Vozes, 2008.

CIVIDINI, Fátima Regina; STEFANUTTI, Paola; GREGORY, Valdir. Alimentação e migração: discussões e reflexões teóricas. In: IX ENCONTRO INTERNACIONAL DE LETRAS - IX EILETRAS III SIMPÓSIO TRANSCULTURALIDADE, LINGUAGEM E EDUCAÇÃO. Anais... Foz do Iguaçu: UNIOESTE, 2017. v. 1, p. 1000-1011.

CONTRERAS, Jesús; GRACIA, Mabel. Alimentação, sociedade e cultura. Tradução: Mayra Fonseca e Barba Atie Guidalli. Rio de Janeiro: Editora Fiocruz, 2011.

DI RENZO, Ernesto. La cucina da Adrià a nonna Peppinella. Il Centro, Pescara, 7 nov. 2019. Lo sguardo dell' antropologo, p. 10, 2019.

DIRECCIÓN GENERAL DE ESTADÍSTICA, ENCUESTAS Y CENSOS. 2015. Disponível em: <http://www.dgeec.gov.py/>. Acesso em: 07 nov. 2020.

FERNANDES, Caloca. Viagem gastronômica através do Brasil. Design Sylvia Monteiro. 8 ed. São Paulo: Editora Senac São Paulo/Editora Estúdio Sonia Robatto, 2007.

FOZ DO IGUAÇU. Secretaria Municipal de Turismo. Inventário Técnico de Estatísticas Turísticas. Foz do Iguaçu: SMTU, 2014.

FOZ DO IGUAÇU. Pratos Típicos. Disponível em: <http://www.pmfi. pr.gov.br/turismo/\%3Bjsessionid\%3D3797854c4e16d0c8125784fb62c4?idMenu=1698>. Acesso em: 12 ago. 2019.

FOZ DO IGUAÇU. Agência de Notícias Governo Municipal de Foz do Iguaçu. Projeto Feira Livre das Nações. Disponível em: <http://www. pmfi.pr.gov.br/noticia/?idNoticia=36904> . Acesso em: 13 abr. 2019.

GINZBURG, Carlo. Mitos, emblemas, sinais: morfologia e história. Tradução: Federico Carotti. São Paulo: Companhia das Letras, 1989.

GINZBURG, Carlo. O queijo e os vermes: o cotidiano e as ideias de um moleiro perseguido pela Inquisição. Tradução: Maria Betânia Amoroso. 8 ed. São Paulo: Companhia das Letras, 2006.

GOOGLE. Google Maps. Disponível em: <https://www.google.com.br/ maps/>. Acesso em: 21 abr. 2019.

HALL, Stuart. A Identidade Cultural na Pós-Modernidade. $11^{\mathrm{a}}$ ed. Rio de Janeiro: DP\&A, 2006. 
HAESBAERT, Rogério. O mito da desterritorialização. Rio de Janeiro: Bertrand Brasil, 2004.

HECK, Marina; BELLUZZO, Rosa. Cozinha dos Imigrantes: Memórias \& Receitas. São Paulo: Editora DBA, 1998.

HOBSBAWM, Eric John Ernest. Introdução: A invenção das tradições. In: HOBSBAWM, Eric John Ernest; RANGER, Terence Osborn (org.). A invenção das tradições. 3. ed. Rio de Janeiro: Paz e Terra, 2002. p. 9-24.

IPHAN - INSTITUTO DO PATRIMÔNIO HISTÓRICO E ARTÍSTICO NACIONAL. Ofício das baianas de acarajé. Brasília: Iphan, 2007.

MARTINS, José Souza. Fronteira: a degradação do outro nos confins do humano. São Paulo: Contexto, 2009.

MONTANARI, Massimo. Comida como cultura. Tradução: Letícia Martins de Andrade. São Paulo: Editora Senac São Paulo, 2008.

PINHEIRO, Ronaldo Adriano. Entrevista concedida em 02/04/2019 às autoras, em Foz do Iguaçu.

PIRES, João Henrique Souza; ZANELLA, Flavia Meneghim; OLIVEIRA, Maria Rita Marques de. Costumes alimentares dos barrageiros da Itaipu residentes na Vila C. Foz do Iguaçu: Editora Parque Itaipu, 2012.

PORTAL DA CIDADE. Sem previsão de retorno das aulas, estudantes de medicina deixam o Paraguai. Portal da Cidade, Foz do Iguaçu, 24 abr. 2020. Disponível em: <https://foz.portaldacidade.com/noticias/ regiao/sem-previsao-de-retorno-das-aulas-estudantes-de-medicina-deixam-o-paraguai-1453>. Acesso em: 07 nov. 2020.

PUJADAS, Joan Josep. Estado-Nación, movimientos autonómicos y procesos transfronterizos en España. In: ARCE, José Manuel Valenzuela Arce (coord.). Transfronteras: fronteras del mundo y procesos culturales. Tijuana, B.C., México: El Colegio de la Frontera Norte, 2014.

PUJADAS, Joan Josep. Los claroscuros de la etnicidad. El culturalismo evaluado desde la óptica de la cohesión social y la ciudadanía. In: Palenzuela, P.; Olivi, A. (eds). Etnicidad y desarrollo en los Andes. Sevilla: SEPUS, 2011. p. 25-51.

ROCHA, Carla Pires Vieira da; RIAL, Carmen Silvia; HELLEBRANDT, Luceni. Alimentação, globalização e interculturalidade a partir do contexto migratório. Cadernos de Pesquisa Interdisciplinar em Ciências Humanas, Florianópolis, v. 14, n. 105, p. 187-199, 2013.

RURAL, Red. A Central de Produtores e Feirantes Hortigranjeiros no Paraguai. Revista Agriculturas, v. 13, n. 3, p. 56-64, 2016.

SANTOS, Clenise Maria Reis Capellani dos. A alimentação como processo de integração da comunidade Árabe em Foz do Iguaçu. Dissertação (Mestrado) - Universidade Estadual do Oeste do Paraná, Foz do Iguaçu, 2013. 
SGANZERLA, Eduardo; STRASBURGER, Jan. Culinária paranaense. Curitiba: Editora Esplendor, 2004.

STEFANUTTI, Paola. Do couvert ao café: pescadores, memórias e comidas. Dissertação]. Foz do Iguaçu: Universidade Estadual do Oeste do Paraná; 2015.

STEFANUTTI, Paola. Das feiras às culturas alimentares (no plural) da tríplice fronteira. [tese]. Dissertação (Mestrado) - Universidade Estadual do Oeste do Paraná, Foz do Iguaçu, 2020.

TILLEY, Christopher. Identity, Place, Landscape and Heritage. Journal of Material Culture, v. 11, n. 1/2, p. 7-32, 2006.

WELTER, Viviane. A hospitalidade e o controle na fronteira entre o Brasil, o Paraguai e a Argentina sob a perspectiva do turista brasileiro. Dissertação (Mestrado) - Universidade Estadual do Oeste do Paraná, Foz do Iguaçu, 2018.

YU, Michele Siu Mui. Presença das línguas chinesas e integração de chineses em diversos espaços sociais de Foz do Iguaçu - PR: um estudo interdisciplinar. Dissertação (Mestrado) - Universidade Estadual do Oeste do Paraná, Foz do Iguaçu, 2018.

SUBMETIDO EM: $14 / 11 / 2020$

APROVADO EM: 21/04/2021 